\title{
Os reflexos do HIV na vida do jovem soropositivo
}

\author{
The reflexes of HIV in the life of the seropositive young person \\ Los reflejos del VIH en la vida del joven seropositivo
}

Recebido: 24/05/2021 | Revisado: 01/06/2021 | Aceito: 05/06/2021 | Publicado: 20/06/2021

\author{
Ana Carolina da Costa Correia Lima \\ ORCID: https://orcid.org/0000-0002-7253-6141 \\ Universidade Estadual do Rio de Janeiro, Brasil \\ E-mail: Carol_cclima@hotmail.com \\ Karine Machado Cascaes \\ ORCID: https://orcid.org/0000-0001-6512-3544 \\ Universidade Estadual do Rio de Janeiro, Brasil \\ E-mail: Karine_cascaes@hotmail.com \\ Inez Silva de Almeida \\ ORCID: https://orcid.org/0000-0001-5082-5607 \\ Universidade Estadual do Rio de Janeiro, Brasil \\ E-mail: inezalmeida2016@gmail.com \\ Andréia Jorge da Costa \\ ORCID: https://orcid.org/0000-0001-6923-4401 \\ Universidade Federal do Estado do Rio de Janeiro, Brasil \\ E-mail: andreiajcosta@msn.com \\ Priscila Cristina da Silva Thiengo de Andrade \\ ORCID: https://orcid.org/0000-0003-0840-4838 \\ Universidade Estadual do Rio de Janeiro, Brasil \\ E-mail: profprithiengo@gmail.com \\ Juliana de Souza Fernandes \\ ORCID: https://orcid.org/0000-0001-9556-798X \\ Universidade Estadual do Rio de Janeiro, Brasil \\ E-mail: julianasouzafernandes@hotmail.com \\ Helena Ferraz Gomes \\ ORCID: https://orcid.org/0000-0001-6089-6361 \\ Universidade Estadual do Rio de Janeiro, Brasil \\ E-mail: helenafg1@yahoo.com.br \\ Ellen Márcia Peres \\ ORCID: https://orcid.org/0000-0003-4262-6987 \\ Universidade Estadual do Rio de Janeiro, Brasil \\ E-mail: ellenperes@globo.com \\ Vinicius Rodrigues de Souza \\ ORCID: https://orcid.org/0000-0001-8035-3647 \\ Universidade Federal Fluminense, Brasil \\ E-mail: viniciussouza.enf@gmail.com \\ Geilsa Soraia Cavalcanti Valente \\ ORCID: https://orcid.org/0000-0003-4488-4912 \\ Universidade Federal Fluminense, Brasil \\ E-mail: geilsavalente@gmail.com
}

\begin{abstract}
Resumo
Objetivo: Compreender os reflexos do HIV/aids na vida de jovens soropositivos. Metodologia: Pesquisa qualitativa, descritiva e exploratória realizada com 11 jovens atendidos em um ambulatório especializado em saúde do adolescente. Utilizou-se como instrumento de coleta de dados a entrevista semiestruturada a partir de perguntas com finalidade de traçar o perfil dos jovens, bem como abordar experiências vividas após o diagnóstico da doença. Os dados foram analisados e agrupados em três categorias temáticas, sendo discutidos à luz de estudiosos ligados à temática. Resultados: Compreendeu-se sobre os sentimentos que o diagnóstico de HIV/aids traz a vida de jovens, especialmente, pela associação da doença à morte e ao preconceito. Conclusão: Este estudo permitiu elucidar a questão de que, para trabalhar com jovens soropositivos na área da saúde, é necessário que o enfermeiro fortaleça o vínculo com os usuários, promovendo um acolhimento eficaz, se utilizando de sensibilidade e empatia para reduzir os efeitos desagradáveis acerca da doença e atenuar o sofrimento durante o tratamento e acompanhamento do jovem.
\end{abstract}

Palavras-chave: Adulto jovem; Síndrome da imunodeficiência adquirida; Enfermagem; Emoções.

\section{Abstract}

Objective: To understand the impact of HIV / AIDS in the lives of HIV positive young people. Methodology: Qualitative, descriptive and exploratory research carried out with 11 young people attended at an outpatient clinic 
specialized in adolescent health. A semi-structured interview was used as a data collection instrument based on questions in order to outline the profile of young people, as well as to address experiences lived after the diagnosis of the disease. The data were analyzed and grouped into three thematic categories, being discussed in the light of scholars linked to the theme. Results: It was understood about the feelings that the diagnosis of HIV / AIDS brings to the lives of young people, especially due to the association of the disease with death and prejudice. Conclusion: This study made it possible to elucidate the question that, in order to work with HIV-positive young people in the health area, it is necessary for nurses to strengthen the bond with users, promoting an effective reception, using sensitivity and empathy to reduce the unpleasant effects on of the disease and mitigate the suffering during the treatment and follow-up of the young person.

Keywords: Young adult; Acquired immunodeficiency syndrome; Nursing; Emotions.

\section{Resumen}

Objetivo: Comprender el impacto del VIH / SIDA en la vida de los jóvenes seropositivos. Metodología: Investigación cualitativa, descriptiva y exploratoria realizada con 11 jóvenes atendidos en un ambulatorio especializado en salud del adolescente. Se utilizó una entrevista semiestructurada como instrumento de recolección de datos, a partir de preguntas con el fin de delinear el perfil de los jóvenes, así como abordar las experiencias vividas luego del diagnóstico de la enfermedad. Los datos fueron analizados y agrupados en tres categorías temáticas, siendo discutidos a la luz de estudiosos vinculados al tema. Resultados: Se entendió sobre los sentimientos que el diagnóstico de VIH / SIDA trae a la vida de los jóvenes, especialmente por la asociación de la enfermedad con la muerte y el prejuicio. Conclusión: Este estudio permitió dilucidar la pregunta de que, para trabajar con jóvenes VIH positivos en el área de la salud, es necesario que las enfermeras fortalezcan el vínculo con los usuarios, promoviendo una recepción efectiva, utilizando la sensibilidad y la empatía para reducir los efectos desagradables sobre la enfermedad y mitigar el sufrimiento durante el tratamiento y seguimiento del joven.

Palabras clave: Adulto joven; Síndrome de inmunodeficiencia adquirida; Enfermería; Emociones.

\section{Introdução}

O presente estudo teve como objeto os reflexos do vírus da imunodeficiência humana (HIV) na vida do jovem soropositivo, visto que esta é uma epidemia marcada pelo medo, preconceito e estigma social e que tem reflexos diretos nas vidas destes jovens e na forma como eles se relacionam com os outros.

O HIV é conhecido por ocasionar a síndrome da imunodeficiência adquirida (AIDS), que por sua vez, é um desequilíbrio no sistema imunológico do indivíduo acometido, onde corresponde a sintomas clínicos por conta de uma vulnerabilidade excessiva a infecções oportunistas (Teixeira et al., 2020). Um dos seus principais atributos é a redução nas células T CD4 (Goulart et al., 2018).

Segundo Gonçalves et al., (2020) a infecção pelo HIV continua sendo uma questão social de relevância em todo o mundo. Estimativas relatadas pela Organização Mundial de Saúde (OMS) sugeriram que 36,9 milhões de pessoas viviam com o HIV e AIDS no final de 2017, tendo 1,8 milhão de novas infecções e 940 mil mortes por causas relacionadas ao HIV (Unaids, 2018).

Para Brasil (2017), a taxa de infecção pelo HIV/aids vem diminuindo em todas as idades, porém mais da metade dos novos casos ocorrem entre as idades de 15 aos 24 anos. Além das questões inerentes a fisiopatologia do HIV/aids, existem outros pontos importantes da vida do jovem que os profissionais de saúde deveriam se atentar, exemplificando, o desconhecimento da patologia e os reflexos dela em todos os âmbitos da vida.

O período da juventude é um período de descobertas. É a fase de crescimento e desenvolvimento, cujas transformações físicas e psíquicas são as mais notáveis. Nesta etapa, surgem constantes dúvidas, busca por identidade e evolução pessoal. Spindola et al., (2015) reforça que é nessa fase que se começa o entendimento sobre o que é doença. Para eles é mais difícil aceitar as doenças, principalmente quando altera as suas atividades diárias e o seu relacionamento com outras pessoas.

Além disso, Villarinho e Padilha (2016) informa que o jovem HIV positivo passa por toda essa fase de descobertas convivendo com essa patologia que sofre ainda muito estigma e envolve dimensões delicadas, que necessitam ser reconhecidas 
e legitimadas pelos profissionais que os acompanham. Desde o seu surgimento, a epidemia da aids, por ser uma doença vinculada ao homossexualismo e a promiscuidade, vem sendo acompanhada por situações de discriminação.

Nesse sentido, o impacto na vida do jovem portador do HIV pode se manifestar através da baixa autoestima, repressão da afetividade, medo da discriminação e a baixa procura por ajuda e tratamento. Sentimentos como medo, revolta e rejeição se destacam, bem como a vergonha e o isolamento que muitas vezes causa estados depressivos. Influenciados pelo meio social, rapazes e garotas podem evitar as relações afetivas considera possuir algo que é nocivo ao outro (Miziara e Andrade, 2016).

Para mostrar relevância ao presente estudo, realizou-se uma busca nas bases de dados da Biblioteca Virtual em Saúde utilizando os seguintes descritores: HIV/ Aids; Enfermagem e Adulto jovem. Aplicou-se os filtros de artigos completos disponíveis no idioma português e com publicações entre os anos de 2015 a 2019. Foram encontrados 25 artigos que após leitura criteriosa dos mesmos, identificou-se que nenhum deles se adequaram a proposta do estudo em tela. Sendo assim, foi possível observar uma carência de estudos que tratavam dos reflexos do vírus do HIV na vida do jovem soropositivo.

Com isso, o objetivo do estudo foi compreender os reflexos do HIV/Aids na vida de jovens soropositivos.

\section{Metodologia}

Trata-se de um estudo qualitativo, descritivo e exploratório, orientado pela seguinte questão norteadora: Como o jovem soropositivo percebe o HIV em sua vida? Para Ludke e Andre (2013), a pesquisa de abordagem qualitativa utiliza o método da intuição e subjetividade, apresentando variáveis que não podem ser quantificadas, contudo são mais maleáveis e de fácil determinação baseando-se nas observações que serão interpretadas e codificadas, obtidas através do contato direto do pesquisador com o fenômeno.

O cenário do estudo foi um ambulatório especializado no atendimento de jovens, de um Hospital Público Universitário na cidade do Rio de Janeiro. Este estudo é oriundo do Núcleo de Estudos da Saúde do Adolescente da Universidade do Estado do Rio de Janeiro (UERJ), tendo sido aprovado pelo Comitê de Ética e pesquisa do Hospital Universitário Pedro Ernesto sob o parecer n 3.825.078.

Os participantes da pesquisa foram 11 jovens que convivem com o HIV em tratamento na unidade ambulatorial, sendo 6 rapazes e 5 moças. Foram estabelecidos os seguintes critérios de inclusão: I) Conviver com o HIV; II) Ter mais de 18 anos e menos de 29 anos; III) Estar em tratamento no ambulatório especializado de jovens com HIV. Excluiu-se do estudo os jovens que abandonaram o tratamento durante o período da coleta de dados.

Utilizou-se como instrumento de coleta de dados a entrevista semiestruturada a partir de perguntas com finalidade de traçar o perfil dos jovens, bem como abordar experiências vividas após o diagnóstico da doença. A coleta de dados foi aconteceu no período compreendido entre fevereiro a agosto de 2020.

Ao iniciar a entrevista, os depoentes foram orientados sobre a pesquisa e o objetivo do estudo. Foi apresentado o Termo de Consentimento Livre e Esclarecido (TCLE), dando-lhe o livre arbítrio de participar ou não do estudo, sem prejuízos para sua relação e o atendimento profissional na instituição. As entrevistas foram gravadas através de um dispositivo de telefone celular. Logo após, foram apresentadas para os participantes da pesquisa, objetivando receber o aval dos mesmos.

Para garantir o anonimato, foi atribuído um código numérico aos participantes, denominado pela letra "J" de jovens, e por algarismos arábicos seguindo a ordem de realização das entrevistas. Logo, os participantes foram identificados como J1, J2, J3, sucessivamente.

Para a interpretação e análise dos dados, optou-se pela análise temática por ser a mais apropriada para pesquisas em saúde, desdobrando-se nas etapas de pré-análise, exploração do material ou codificação e tratamento dos resultados obtidos/ interpretação (Minayo, 1996). 


\section{Resultados e Discussão}

Foram realizadas 11 entrevistas, com 6 rapazes e 5 moças. Quanto à escolaridade, foi verificado o atraso escolar entre 6 dos 11 entrevistados, 3 relataram ter o ensino médio completo e 2 estavam cursando ensino superior. Dos 11 jovens participantes, 7 disseram trabalhar.

Em relação à etnia, 4 se consideraram brancos, 4 pardos e 3 negros. Quando questionados se possuíam religião, 4 declararam não seguir uma específica, 2 seguiam o catolicismo, 2 o espiritismo, 1 o evangelismo e 1 o agnosticismo.

Sobre à orientação sexual dos entrevistados, 7 disseram se relacionar com pessoas do sexo oposto, 3 declararam relacionar-se exclusivamente com pessoas do mesmo sexo e 1 jovem relatou relacionar-se com ambos os sexos.

No que tange ao estado civil, 4 são casados, 4 namoram e 3 são solteiros. Quando questionados com quem moravam, 4 relataram com seu (sua) companheiro (a), 4 com a família (mãe, pai, irmão e tia), 1 disse morar sozinho e 1 com amigos.

Foram levantados também a região em que os participantes do estudo moravam. Todos residiam no estado do Rio de Janeiro, sendo 4 na zona norte, 3 na região metropolitana, 1 na baixada fluminense, 1 na zona oeste e um 1 na região central.

Diante do objetivo traçado para a pesquisa e dos dados obtidos que foram confrontados entre si, a partir das narrativas dos entrevistados, surgiram 3 categorias empíricas, a saber: Dificuldade de aceitar o diagnóstico; vivenciando o preconceito e $\mathrm{O}$ (des)conhecimento das outras pessoas sobre o HIV.

\section{Categoria I - A dificuldade de aceitar o diagnóstico}

Foram classificados nessa categoria as falas de sentimentos negativos, medos e inseguranças que o diagnóstico trouxe para esses jovens, bem como a dificuldade que tiveram para aceitar a doença. Esse momento é citado por mais da metade dos jovens entrevistados como um divisor de águas em suas vidas, deixando claro como essa questão trouxe sentimentos e repercussões negativas e de incertezas. Alguns jovens relataram sobre a dificuldade de descobrir a doença na adolescência, dificuldade de aceitação do tratamento para o resto da vida e o medo da morte. Vejamos algumas falas que mostram esses sentimentos:

"Tomei um baque e falei minha vida acabou." J2

"No começo para mim foi um choque (...) Eu acho que foi um castigo (...) Na hora eu pensei que estava no fundo do buraco. " J4

Atualmente, a principal forma de informação que o jovem busca ao descobrir seu diagnóstico é a internet, porém, ainda há um grande atraso relacionado ao tema. Pinto et al., (2016) destaca que é importante que os enfermeiros, como promotores da saúde, disseminem conhecimentos sobre a síndrome para a população em geral, potencializando seus conhecimentos. Abordar essa temática através de informações claras sobre IST e HIV/aids, são de grande importância para que assim, o jovem seja o protagonista de sua própria história, rompendo com a cadeia de transmissão do preconceito.

"Minha mãe foi conversando comigo, eu não aceitava(...) '”. J5

"Só o fato de a pessoa descobrir jovem, já é um impacto complicado. Não é algo fácil de se conversar, porque nem todo mundo se abre assim, nem sei como dizer..." J7

A AIDS e a descoberta do diagnóstico de soropositividade conduz ao grande impacto na vida dos jovens. As mudanças que ocorrem, a partir dessa revelação, possibilitam o surgimento de sentimentos de sofrimento e estresse. Traumas são comuns, levando ao pânico, bem como, problemas sociais e psicológicos. O receio e as dúvidas diante da nova realidade 
com que o jovem se depara fazem com que sejam aflorados os sentimentos de insegurança e pavor.

"Quando eu descobri... Eu pensei que ia morrer, aquela droga que você toma." J6

A reação e o sofrimento diante do diagnóstico positivo e do medo da morte, ocorrem mediante os preconceitos estimulados ao longo da vida, pela associação da sexualidade com a promiscuidade no interior da família e da sociedade (Thiengo et al, 2017).

"Quando eu descobri eu tinha 13 anos, não entendia nada direito. Mas, mesmo assim foi um choque, porque na época só o que eu sabia é que eu deveria tomar remédio para a vida toda." J9

"Quando eu descobri, realmente a primeira coisa que vem na nossa cabeça é que a gente vai morrer. (...) Eu nem conseguia falar do assunto. Essa palavra HIV é muito forte pra mim, isso me abala muito até hoje (...) porque eu não aceito, né?" J11

Para Almeida et al., (2020), ao receber o resultado do teste positivo, o jovem tem a certeza de que, junto ao HIV/Aids, vem a sentença de morte. É uma síndrome que carrega inúmeras inquietações, principalmente por abarcar em si preconceitos e discriminação. Assim, familiares e até mesmo profissionais de saúde, relutam em revelar a real condição de saúde, o que traz uma realidade preocupante, por influenciar diretamente no prognóstico.

Os jovens que convivem com o HIV têm consciência de que os sintomas irão surgir, o que representa não ser possível negar a sua condição de soropositividade. Santos et al., (2019) corrobora que esse fenômeno desvela o temor e a ameaça da morte, devido às crenças e atitudes da população, o que terá consequências físicas e psicológicas para os jovens.

Nas pessoas vivendo com o HIV/aids (PVHA) o medo da morte é um sentimento persistente, produz estresse e manifestações psicológicas. Um dos principais motivos são as memórias do início da epidemia, em que a morte ainda era uma sentença de interrupção da vida das pessoas que vivenciam a síndrome (Oliveira, et al 2015).

O diagnóstico é o contato mais próximo do jovem que convive com o HIV/aids, e é também o momento em que surgem os primeiros sentimentos. Reis et al., (2017) explica que moças e rapazes retratam o sofrimento diante da soropositividade frente ao processo do adoecimento. Essas primeiras impressões, pelas narrativas dos entrevistados, são de medo, sensação de que terão uma vida curta e outras pré-concepções relacionadas à doença.

\section{Categoria II - Vivenciando o preconceito}

O preconceito relacionado à soropositividade foi encontrado na fala da maioria dos entrevistados, os quais alegaram experiências de preconceito que já viveram e sentimentos de medo em sofrerem algum tipo de discriminação. Os participantes também demonstraram receio e temem as atitudes das outras pessoas, caso descubram de sua condição. Esses traumas foram expostos nas seguintes falas:

"Você tem que se preocupar com você, e se preocupar sim com o pensamento das outras pessoas, pois você acaba sofrendo algum tipo de preconceito por conta disso." J6

Os entrevistados mencionaram que a ignorância, falsas crenças e pouca informação por parte da sociedade contribuem para o aumento do preconceito. Relataram também que as pessoas têm concepções errôneas e ultrapassadas sobre a doença e acabam tendo atitudes e fazendo comentários constrangedores para esses jovens. 
"Porque tem pessoas que, sabe? tem aquele preconceito. Eu acho que não da minha parte, mas na parte deles, das outras pessoas." J3

“Tem muito preconceito. (...) Já aconteceu preconceito da pessoa não emprestar copo, de não emprestar talher. Tenho medo de acontecer essas coisas comigo e por isso costumo não falar do meu diagnóstico." J8

O diagnóstico traz em seu bojo questões como: a quem contar sobre a condição sorológica? Revelar ou não ao(a) namorado(a)? Os familiares irão compreender? A escolha em guardar segredo, até mesmo dos amigos mais próximos, é a forma que o jovem tem de evitar julgamentos acerca de sua sorologia, porém podem prejudicar sua capacidade e vontade de acessar e aderir ao tratamento (Unaids, 2018)

"Fui começando a ter medo do preconceito. E eu não sofri tantos, mas o único que eu sofri me dói e me marca até hoje. Foi quando eu fui no hospital colher o exame e uma moça falou que não ia colher o meu sangue, porque ela não colhe o sangue de pessoas que nem eu. Falou que eu era um lixo, que pessoas assim já sabia que não iam viver uma vida normal, igual as outras (...). Nos relacionamentos, eu sempre tive medo de contar e a pessoa não aceitar e terminar (...). Sempre tem essa questão do preconceito. Depois que eu descobri, eu sempre tive medo de falar.” J9

Para Agostini, Maksud e Franco (2017) administrar a condição sorológica no contexto dos relacionamentos afetivos também aparece como uma atividade que demanda, por parte dos jovens, muito esforço. A escolha dos jovens por não comunicar o diagnóstico, imediatamente, quando começam a se relacionar com alguém e o desejo de estabelecer vínculos de confiança antes, confirma o medo que eles sentem de serem rejeitados. O momento da revelação para o namorado/a é tido como um ponto de tensão e de muita dificuldade. Isto corrobora a ideia de que as relações do jovem que convive com o HIV/aids são afetadas.

"Tem gente que é ignorante e mesmo você explicando, dando todos os detalhes, ela continua com o preconceito que não tem necessidade." J10

Esses autores ainda complementam que, mesmo com o avançar das pesquisas sobre tratamentos, formas de transmissão, e com o aumento da propagação dessas informações, o medo irracional da doença continua alimentando as atitudes negativas e, até mesmo, a violência velada ou real.

“Ainda tem o preconceito que o HIV é uma doença de homossexual." J11

O preconceito sobre a doença faz com que os indivíduos que convivem com o HIV se tornem carregadas de sentimentos de culpas que não podem reverter - culpa que os familiares, amigos e a sociedade reforçam com cobranças, discriminação, isolamento e omissão.

Adquirir o HIV repercute em uma transgressão ao favorecer um estereótipo que justifica acusações e comportamentos de ameaças aos indivíduos por ser uma doença tão temida. Esses comportamentos seriam a consequência do que é aprovado, de forma negativa, por certos grupos de pessoas como forma de punição moral pelo pecado (Reis, 2017).

Nesse sentido, Beloqui (2019) destaca que para os jovens que vivem com HIV, o conhecimento de que seu status sorológico é um aspecto socialmente desvalorizado, que pode ser experienciado de várias maneiras, desde ser objeto de preconceito e discriminação de outras pessoas até ter crenças negativas acerca de si mesmos. 
Apesar de o tema aparecer como uma categoria separada, pode-se afirmar que o preconceito está presente em todos os pontos analisados nesta pesquisa, perpassando todas as demais categorias analisadas.

\section{Categoria III - O (des)conhecimento das outras pessoas sobre o HIV}

Nesta categoria estão as narrativas que competem à falta de conhecimento das pessoas sobre o HIV. Nossos interlocutores referem que a desinformação aumenta o preconceito e o estigma. Para se protegerem do preconceito, eles preferem não revelar o diagnóstico. Segundo os entrevistados, a falta de informação contribui que as pessoas continuem disseminando inverdades sobre a doença, como por exemplo, a forma de transmissão que alguns ainda acreditam se dar por meio de beijo na boca e compartilhamento de talheres.

"Porque nem todo mundo entende e você não precisa contar pra todo mundo, não tem nem obrigação (...) As pessoas são muito ignorantes..." J6

Abubakar et al., (2016) explicita que a desinformação sobre a AIDS ocorre pela ausência de programas educativos específicos para os jovens sobre a síndrome. Informações incompletas e deturpadas, veiculadas pela mídia, aliadas ao fato de que a AIDS é uma infecção sem cura até o momento, ainda originam valores que interferem negativamente em sua qualidade de vida. Ter uma rede de apoio dos pais e amigos, com quem eles possam compartilhar, ajudaria a superar sua angústia. Além disso, a escassez de serviços especializados, podem ser consideradas barreiras para o conhecimento.

"Porque as pessoas, às vezes, não sabem muito a fundo, como posso dizer... são meio leigas. Ah, beijo na boca, não sei o que... pega." J8

O desconhecimento a respeito das formas de transmissão do HIV, promovem equívocos desde o início do aparecimento da doença, acirrando atitudes desfavoráveis em relação àqueles que foram infectados pelo HIV, tal como tem ocorrido com outras IST.

Os jovens, embora tenham mais acesso à informação, têm menos instrumentos para obter sua compreensão, porque não há investimentos em educação sexual. As escolas e as famílias não conseguem dialogar sobre a temática sexualidade, assim como a sociedade também não o faz. Os jovens, por estarem em um contexto de vulnerabilidades, numa fase de descobertas e experimentações, maior envolvimento social e desenvolvendo os relacionamentos sexuais cada vez mais precoces, são os que mais sofrem com as consequências dessa e outras IST (Brasil, 2017).

"As pessoas lá fora são muito leigas, o entendimento da doença (...) As pessoas ainda tem muito a imagem do Cazuza, daquela doença que tem emagrecimento, que vai morrer (...) Eu já ouvi isso em ambientes de trabalho, de comer no mesmo lugar, essas coisas que ainda tem muita gente que pensa isso. E até dentro da área da saúde, as pessoas ainda são muito leigas. Eu fico ouvindo calada, não falo nada." J11

É de conhecimento que, com a adesão ao tratamento, é possível viver com HIV e ser saudável, ter relacionamentos, filhos e exercer a sexualidade (desde que seja com a proteção adequada). Infelizmente, mesmo com a distribuição de preservativos e medicamentos disponíveis, através do Sistema Único de Saúde (SUS), ainda há um número significativo de pessoas infectadas por HIV, que apresentam recidivas de internações pela não aderência aos antirretrovirais. 


\section{Conclusão}

Com este estudo foi possível compreender como os jovens soropositivos percebem o HIV/aids em suas vidas. De forma geral, destacam-se no conjunto dos relatos dos entrevistados, o sofrimento que o diagnóstico de HIV/aids traz, especialmente pela associação da doença ao preconceito, seja dos próprios sujeitos, seja de outras pessoas. Além disso, apesar dos avanços de estudos na área, percebeu-se que ainda existe muita desinformação, o que colabora para a manutenção do preconceito.

Foi possível identificar também que a infecção do HIV acarreta reflexos na vida desses jovens, acarretando prejuízos na sua autoestima, autoimagem, autorrealização e no relacionamento interpessoal. Nesse sentido, para que o acompanhamento desse jovem seja eficaz, é fundamental que os profissionais que prestem atendimento a esse grupo formem vínculos. O acolhimento, a sensibilidade, a escuta ativa e a empatia são imprescindíveis para a redução dos efeitos desagradáveis acerca da doença.

Diante do exposto, o estudo traz contribuições para a assistência de enfermagem à ótica dos jovens que convivem com o HIV/aids, na medida em que identifica a importância de os enfermeiros compreenderem as demandas emitidas por esses jovens, além da necessidade de promover estratégias que fortaleçam e qualifiquem o cuidado.

Em suma, sugere-se que esses novos estudos tragam uma visão mais integral e holística por parte de enfermeiros e profissionais de saúde que estão inseridos no cuidado a jovens portadores do HIV. Torna-se necessária novas pesquisas que contemplem a subjetividade desses indivíduos, alcançando fenômenos íntimos e sentimentais que interferem no bemestar físico, mental e intelectual.

\section{Referências}

Abubakar, A., Van de Vijver, F. J., Fischer, R., Hassan, A. S., Gona, J. K., Dzombo, J. T., \& Newton, C. R. (2016). 'Everyone has a secret they keep close to their hearts': challenges faced by adolescents living with HIV infection at the Kenyan coast. BMC public health, 16(1), 1-8. https://doi.org/10.1186/s12889-016-2854-y

Agostini, R., Maksud, I., \& Franco, T. (2017). "Essa doença para mim é a mesma coisa que nada": reflexões socioantropológicas sobre o descobrir-se soropositivo. Saúde e Sociedade, 26, 496-509. https://doi.org/10.1590/S0104-12902017170072

Almeida, I. S., Assis, G. P. S., Gomes, H. F., Costa, A. J., Carvalho, E., \& Soares R. R. P. (2020). Percepção de indivíduos soropositivos acerca da revelação do diagnóstico de HIV na adolescência. Adolesc Saude, 17(2):1-6. https://cdn.publisher.gn1.link/adolescenciaesaude.com/pdf/v17n2a08.pdf

Brasil (2017). Ministério da Saúde. Cuidado integral às pessoas que vivem com HIV pela Atenção Básica. http://www.aids.gov.br/pt-br/pub/2016/cuidadointegral-pessoas-que-vivem-com-hiv-pela-atencao-basica.

Brasil (2017). Ministério da Saúde. Saúde e sexualidade de adolescentes. http://bvsms.saude.gov.br/bvs/publicacoes/saude sexualidade adolescente construindo e equidade sus.pdf.

Beloqui, Jorge A. Brasil: Violência e Discriminação em Pessoas Vivendo com HIV/AIDS (2019). A perspectiva dos membros da RNP+ Rede Nacional de Pessoas Vivendo com HIV e AIDS, São Paulo.

Gonçalves, G. F., Cordeiro, B. C., Dias, M. M., \& Messias, C. M. (2020). Educação permanente na assistência farmacêutica ao paciente com HIV: uma revisão integrativa. Research, Society and Development, 9(3), e70932426-e70932426. https://doi.org/10.33448/rsd-v9i3.2426

Goulart, L. S., Souza, W. W. R. D., Vieira, C. A., Lima, J. S. D., Olinda, R. A. D., \& Araújo, C. D. (2018). Oral colonization by Candida species in HIVpositive patients: association and antifungal susceptibility study. Einstein (São Paulo), 16(3). 1-6. DOI: https://doi.org/10.1590/s1679-45082018ao4224

Ludke, M. \& Andre, M. E . D. A. (2013). Pesquisas em educação: uma abordagem qualitativa. E.P.U.

Oliveira, D. C., Spindola, T., Gomes, A. M. T., Marques, S. C., Formozo, G. A., \& de Araujo Campos, L. (2015). Construções simbólicas do tratamento de pessoas que vivem com o HIV/AIDS. Revista Enfermagem UERJ, 23(5), 596-602. http://dx.doi.org/10.12957/reuerj.2015.13191

Santos, É. E. P., Ribeiro, A. C., Langendorf, T. F., de Paula, C. C., \& de Mello Padoin, S. M. (2019). Vivências de jovens em terapia antirretroviral para o HIV: estudo fenomenológico. Avances en Enfermería, 37(3), 323-332. https://doi.org/10.15446/av.enferm.v37n3.78804

Spindola, T., Ribeiro, K. S., \& Fonte, V. R. F. (2015). A vivência da gravidez na adolescência: contribuições para a enfermagem obstétrica. Adolesc. Saude.12(1), 50-6. https://cdn.publisher.gn1.link/adolescenciaesaude.com/pdf/v12n1a08.pdf

Minayo, M. C. D. S. (1996). O desafio do conhecimento: pesquisa qualitativa em saúde. In O desafio do conhecimento: pesquisa qualitativa em saúde (pp. 407-p). 
Research, Society and Development, v. 10, n. 7, e24110716435, 2021

(CC BY 4.0) | ISSN 2525-3409 | DOI: http://dx.doi.org/10.33448/rsd-v10i7.16435

Miziara, L. A. F., \& Andrade, S. M. O. (2016). O significado do HIV/Aids na vida de crianças e adolescentes que vivem com a doença. Boletim Academia Paulista de Psicologia, 36(90), 16-30. https://www.redalyc.org/articulo.oa?id=94649375003

Pinto, A. C. S., Queiroz, M. V. O., do Amaral Gubert, F., Braga, V. A. B., \& da Costa Pinheiro, P. N. (2016). Educação em Saúde na prevenção do HIV/AIDS com homens jovens usuários de crack. Texto \& Contexto Enfermagem, 25(3), 1-9. https://doi.org/10.1590/0104-07072016004070015

Reis, R. K., Castrighini, C. D. C., Melo, E. S., Jesus, G. J. D., Queiroz, A. A. F. L., \& Gir, E. (2017). Avaliação dos sintomas depressivos somáticos e afetivocognitivos de pessoas vivendo com HIV/AIDS. Acta Paulista de Enfermagem, 30(1), 60-65. https://doi.org/10.1590/1982-0194201700009

Teixeira, S. P., de Aguiar, D. S., Nemer, C. R. B., \& de Oliveira Menezes, R. A. (2020). Perfil epidemiológico de gestantes com HIV admitidas em uma maternidade de referência no Amapá. Revista Eletrônica Acervo Saúde, 12(2), e2543-e2543. https://doi.org/10.25248/reas.e2543.2020

Thiengo, P. C.S., Gomes, A. M. T., \& de Oliveira, D. C. (2017). As representações do cuidado voltado à pessoa que vive com HIV/AIDs para a equipe de saúde. Revista Enfermagem Atual In Derme, 82(20). https://doi.org/10.31011/reaid-2017-v.82-n.20-art.302

Unaids (2018). Relatório Informativo - Dia mundial contra a AIDS 2018: estatísticas globais sobre HIV, Organização das Nações Unidas. Disponível em: https://unaids.org.br/estatisticas.

Villarinho, M. V., \& Padilha, M. I. (2016). Sentimentos relatados pelos trabalhadores da saúde frente à epidemia da aids (1986-2006). Texto \& ContextoEnfermagem, 25(1). https://doi.org/10.1590/0104-07072016000010013 